\title{
Prognostic Value of Morphologic and Clinical Parameters in pT2 - pT3 Prostate Cancer
}

\author{
Jose C. Almeida, Raissa P. Menezes, Selma A. Kuckelhaus, Anamelia L. Bocca, Florencio \\ Figueiredo
}

Urologic Clinic of Armed Forces Hospital, Laboratory of Immunopathology and Pathological Anatomy - LIB/Biopsy, School of Medicine, University of Brasilia, School of Medicine, Catholic University of Brasilia, Brasilia, DF, Brazil

\begin{abstract}
Objectives: Verify the efficacy of clinical and morphologic parameters currently applied, including an immunohistochemical panel, in the prognostic of prostate cancer, in specific stages of the disease.

Materials and Methods: In the period from 2002 to 2005, 40 surgical specimens were selected from patients submitted to radical prostatectomy, with their respective diagnostic biopsies. Based on the pathological stage pT2 or pT3, the specimens were separated into two groups, each one with 20 specimens. The results were confronted with pre- and postoperative clinical data. Between the groups studied, the following was also analyzed: the profile of the expression of molecular markers such as PSA, E-caderin, chromogranin-A, synaptofisin, P53 and Ki-67, both in the material coming from the prostatic biopsy and from the surgical specimens of all patients.

Results: Data showed that patients with prostate-confined disease (pT2) presented lower PSA and Gleason score rates, in relation to the group with extra-prostatic disease (pT3). Quantitative measures obtained for the percentage of positive fragments from the biopsy revealed that patients from the pT2 group presented a lower mean percentage when compared to the pT3 group. Positive margins of both groups influenced the need for complementary treatment before biochemical progression. The comparison of the molecular marker expression in both stages was not significantly different.

Conclusion: It is evident the need to improve new methods, predominantly morphologic and molecular, that are able to further exploit the study of the material from the prostatic biopsy. As to the profile of the molecular markers used in both studied groups, there was no significant difference in the sense of outlining an additional prognostic factor in the clinical practice.
\end{abstract}

Key words: prostatic neoplasms; biopsy; prostatectomy; immunohistochemistry; pathology; prognosis

Int Braz J Urol. 2007; 33: 662-72

\section{INTRODUCTION}

Prostate cancer is presented as the second malignant disease most commonly diagnosed in men aged more than 50 years and represents a social problem with an important impact to men's health, for
$3 \%$ of the patients presenting this disease will die, representing in the United States alone approximately 30,200 deaths per year (1).

Prostate cancer incidence presents regional variations and according to the studies of Hsing et al. (2), eastern countries present a lower incidence when 
compared to western countries. The improvement of diagnostic methods associated to screening tests have motivated the development of new ways to anticipate the diagnosis, propose specific treatment, minimize unnecessary treatments (3), and to reduce the high percentage of post treatment biochemical recurrence (4). However, it is important to consider that in patients with normal prostatic digital rectal examination the trend to reduce the PSA cut-off level (bellow $4 \mathrm{ng}$ / $\mathrm{mL}$ ), could lead to the treatment of the so-called insignificant tumors (5).

PSA levels, Gleason score and TNM staging are established and considered essential to the prognostic of prostate cancer, when analyzed separately or jointly (6). Other factors such as the additional clinicalmorphologic ones and molecular markers can also contribute substantially (7). Among the factors related to the biopsy, the percentage of positive fragments has presented a positive correlation with the potential risk of biochemical progression after treatment (8).

Today, there is a big concern regarding the research of new prognostic criteria with clinical applicability that precisely define recurrence risk, survival rate and the appropriate medical orientation, for both clinical follow-up and active treatment. In malignant neoplasia, there is a need to go beyond the diagnosis and search information about the most efficient prognostic and therapy for the disease (9). Up to now, clinical factors have offered the basis to build different nomograms that establish the risk and the evolution of the disease. However, before the variability of molecule expression in prostate cancer, the molecular basis and protein expression are not contemplated by these models (10).

The present study tried to assess in locally confined disease (pT2) with extra-prostatic extension (pT3), the efficiency of clinical and morphologic parameters of prognostic presently applied in prostate cancer, correlating them through immunohistochemistry, with proliferation indexes, cellular adhesion and neuroendocrine differentiation.

\section{MATERIALS AND METHODS}

In the period from 2002 to 2005,40 surgical specimens from patients submitted to radical prostatectomy were selected. When surgical indication was given, all patients presented a clinical stage of localized prostate cancer $(\mathrm{T} 1 \mathrm{c} / \mathrm{T} 2 \mathrm{c})$, according to TNM staging system (11). Exclusion criteria involved previous history of hormonal blockage and/or radiotherapy, diagnosis based in material obtained from transurethral resection of the prostate or any clinical evidence of extra-prostatic or metastatic disease.

Selection of surgical specimens was based on the pathological stages pT2 and pT3, which respectively characterize a prostate-confined and extra-prostatic disease. Twenty specimens were selected from each group, being the first, pT2, characterized by specimens from sub-stages pT2a ( 2 patients) and pT2c (18 patients), while the second was formed by pT3a (16 patients) and pT3b (4 patients).

Mean patient's age with pT2 was 62 years and with pT3 was 65.5 years. After radical prostatectomy, the patients were followed in an outpatient clinic every 4 months, based on total PSA serum concentration and for a mean time of 23 months. Value equal or superior to $0.4 \mathrm{ng} / \mathrm{mL}$ was considered as biochemical progression.

Prognostic parameters considered in the preoperative period were age, digital rectal examination, total PSA, free PSA, total of positive fragments on biopsy, positivity percentage per fragment and profile of molecular markers in the prostatic biopsy material. All patients were preoperatively submitted to pelvic computed tomography and bone scintigraphy.

Surgical parameters included positive margins, Gleason score, percentage of positive blocks, pathological stage and molecular markers profile in the surgical specimen.

Indication for ultrasound guided prostatic biopsy, with a removal of an average of 15 fragments, was due to alterations on serum PSA and/or on digital rectal examination.

Biopsy fragments were embedded in paraffin, sectioned and stained with hematoxylin and eosin. Surgical specimens were analyzed by the same pathologist were fixed, stained using India ink and entirely processed by means of a previously established topographic sequence. Characteristics of the surgical specimen and the percentage of positive blocks offered 
the basis for staging and indirect calculation of the tumor volume, according to the protocol of the College of American Pathology (12), and of the American Joint Commission on Cancer (2002) (13).

In the immunohistochemical evaluation, the immunoperoxidase technique was used to identify the PSA, Ki-67, p53, chromogranin-A, synaptofisin and E-caderin.

The variables were analyzed by the Kolmogorov-Smirnov test. Statistical tests applied to compare two groups were t-Student for parametric quantitative data and Mann-Whitney for the nonparametric ones. Qualitative data were assessed by the Fisher method and correlation between quantitative data by the Spereman method. The analyses were performed in the SigmaStat program (Jandel Scientific, San Rafael, CA) and the graphics in the Microcal Microcal $^{\mathrm{TM}}$ Origin $6.0{ }^{\circledR}$ (Microcal Software Inc.
1999). Values of $\mathrm{p}<0.05$ were considered statistically significant.

\section{RESULTS}

In both the pre and postoperative phases of the disease different clinical and morphological factors in the same stage were studied and correlated as well as between both stages studied (pT2 e pT3). The results obtained in the preoperative phase for stage pT2 (PSA, digital rectal examination, percentage of positive fragments of the biopsy percentage of positivity for the fragment and immunohistochemical study of the biopsy) were studied and correlated to prognostic factors (clinical/morphological) of the postoperative phase, predominantly the data obtained from the analysis of the surgical specimen. The same study

Table 1 - Clinical and morphologic pre and postoperative data of the patients submitted to radical prostatectomy and classified as pT2.

\begin{tabular}{|c|c|c|c|c|c|c|c|c|}
\hline Age & $\begin{array}{c}\text { PSA T } \\
(\mathrm{ng} / \mathrm{mL})\end{array}$ & $\begin{array}{c}\% \\
\text { Fragments }\end{array}$ & $\begin{array}{l}\text { Gleason } \\
\text { (biopsy) }\end{array}$ & $\begin{array}{l}\text { TNM } \\
\text { Stage }\end{array}$ & \% Blocks & $\begin{array}{c}\text { Gleason } \\
\text { (surgical specimen) }\end{array}$ & $\begin{array}{l}\text { Positive Margins } \\
\text { (surgical specimen) }\end{array}$ & $\begin{array}{l}\text { Complementary } \\
\text { Treatment }\end{array}$ \\
\hline 64 & 6.4 & 16.7 & $3+4$ & T1c & 20.0 & $3+4$ & no & no \\
\hline 53 & 7.4 & 50.0 & $4+3$ & $\mathrm{~T} 1 \mathrm{c}$ & 87.5 & $3+4$ & no & no \\
\hline 64 & 5.3 & 12.5 & $3+4$ & $\mathrm{~T} 2 \mathrm{a}$ & 10.0 & $3+4$ & no & no \\
\hline 62 & 5.9 & 25.0 & $3+5$ & $\mathrm{~T} 1 \mathrm{c}$ & 63.3 & $3+4$ & yes & no \\
\hline 62 & 5.0 & 50.0 & $3+6$ & $\mathrm{~T} 2 \mathrm{~b}$ & 34.0 & $4+3$ & yes & yes \\
\hline 68 & 5.8 & 66.7 & $3+3$ & $\mathrm{~T} 1 \mathrm{c}$ & 36.0 & $3+5$ & yes & yes \\
\hline 59 & 5.1 & 33.3 & $4+3$ & $\mathrm{~T} 2 \mathrm{~b}$ & 20.0 & $3+4$ & no & no \\
\hline 59 & 8.6 & 85.7 & $4+4$ & $\mathrm{~T} 2 \mathrm{c}$ & 50.0 & $3+4$ & yes & yes \\
\hline 65 & 4.8 & 33.3 & $3+3$ & $\mathrm{~T} 2 \mathrm{~b}$ & 16.7 & $3+4$ & no & no \\
\hline 59 & 3.7 & 16.7 & $3+4$ & $\mathrm{~T} 1 \mathrm{c}$ & 14.5 & $3+4$ & yes & no \\
\hline 62 & 4.4 & 37.5 & $3+4$ & $\mathrm{~T} 2 \mathrm{~b}$ & 27.8 & $4+3$ & no & no \\
\hline 67 & 8.4 & 25.0 & $3+5$ & $\mathrm{~T} 2 \mathrm{~b}$ & 9.7 & $4+3$ & no & no \\
\hline 50 & 4.5 & 16.7 & $3+3$ & $\mathrm{~T} 1 \mathrm{c}$ & 25.8 & $3+4$ & no & no \\
\hline 66 & 5.1 & 8.7 & $3+3$ & T1c & 24.4 & $3+5$ & no & no \\
\hline 59 & 2.8 & 50.0 & $3+4$ & $\mathrm{~T} 2 \mathrm{a}$ & 17.4 & $3+4$ & no & no \\
\hline 45 & 6.4 & 16.7 & $3+3$ & $\mathrm{~T} 2 \mathrm{a}$ & 32.9 & $3+4$ & yes & no \\
\hline 75 & 20.0 & 25.0 & $3+4$ & T1c & 70.0 & $3+4$ & no & no \\
\hline 70 & 29.0 & 28.6 & $3+3$ & $\mathrm{~T} 2 \mathrm{~b}$ & 18.2 & $3+5$ & yes & yes \\
\hline 68 & 3.8 & 33.3 & $3+4$ & $\mathrm{~T} 2 \mathrm{~b}$ & 26.3 & $3+4$ & no & no \\
\hline 62 & 7.3 & 71.4 & $4+3$ & $\mathrm{~T} 2 \mathrm{~b}$ & 53.3 & $3+4$ & no & no \\
\hline
\end{tabular}


Table 2 - Clinical and morphologic pre and postoperative data of the patients submitted to radical prostatectomy and classified as pT3.

\begin{tabular}{|c|c|c|c|c|c|c|c|c|c|}
\hline Age & $\begin{array}{c}\text { PSA T } \\
(\mathrm{ng} / \mathrm{mL})\end{array}$ & $\begin{array}{c}\text { \% Fragments } \\
(+)\end{array}$ & $\begin{array}{l}\text { Gleason } \\
\text { (biopsy) }\end{array}$ & $\begin{array}{l}\text { TNM } \\
\text { Stage }\end{array}$ & $\%$ & $\begin{array}{l}\text { Blocks } \\
(+)\end{array}$ & $\begin{array}{l}\text { Gleason } \\
\text { (surgical specimen) }\end{array}$ & $\begin{array}{l}\text { Positive Margins } \\
\text { (surgical specimen) }\end{array}$ & $\begin{array}{c}\text { Complementary } \\
\text { Treatment }\end{array}$ \\
\hline 64 & 18.0 & 100.0 & $4+5$ & T1c & & 59.2 & $5+4$ & yes & yes \\
\hline 69 & 13.7 & 33.3 & $3+5$ & T1c & & 34.9 & $4+3$ & yes & yes \\
\hline 66 & 9.4 & 57.1 & $3+4$ & $\mathrm{~T} 2 \mathrm{~b}$ & & 27.3 & $3+4$ & yes & yes \\
\hline 68 & 27.0 & 57.1 & $4+3$ & $\mathrm{~T} 2 \mathrm{~b}$ & & 51.8 & $3+4$ & no & yes \\
\hline 73 & 8.0 & 58.3 & $4+3$ & $\mathrm{~T} 2 \mathrm{~b}$ & & 41.4 & $4+3$ & yes & no \\
\hline 70 & 6.1 & 28.6 & $3+5$ & T1c & & 33.9 & $4+3$ & yes & yes \\
\hline 61 & 7.8 & 33.3 & $4+3$ & $\mathrm{~T} 1 \mathrm{c}$ & & 34.0 & $4+3$ & no & no \\
\hline 73 & 6.6 & 33.3 & $4+5$ & T1c & & 26.3 & $4+3$ & no & no \\
\hline 54 & 6.1 & 60.0 & $3+3$ & T1c & & 89.5 & $3+4$ & yes & yes \\
\hline 71 & 23.0 & 66.7 & $5+3$ & $\mathrm{~T} 2 \mathrm{~b}$ & & 87.2 & $3+5$ & yes & yes \\
\hline 58 & 7.3 & 16.7 & $4+4$ & T1c & & 57.6 & $3+4$ & no & no \\
\hline 73 & 9.3 & 66.7 & $3+4$ & $\mathrm{~T} 2 \mathrm{c}$ & & 79.4 & $3+4$ & yes & yes \\
\hline 75 & 10.3 & 58.3 & $4+3$ & T1c & & 35.6 & $3+4$ & yes & yes \\
\hline 69 & 19.0 & 28.6 & $4+3$ & $\mathrm{~T} 2 \mathrm{c}$ & & 73.9 & $3+4$ & yes & yes \\
\hline 56 & 8.5 & 83.3 & $4+3$ & $\mathrm{~T} 2 \mathrm{c}$ & & 76.9 & $3+4$ & yes & yes \\
\hline 65 & 8.8 & 8.3 & $3+3$ & T1c & & 23.4 & $3+5$ & no & no \\
\hline 53 & 6.9 & 28.6 & $4+3$ & $\mathrm{~T} 2 \mathrm{~b}$ & & 21.6 & $4+3$ & no & yes \\
\hline 70 & 45.0 & 50.0 & $4+3$ & $\mathrm{~T} 2 \mathrm{~b}$ & & 44.9 & $4+3$ & no & no \\
\hline 63 & 2.5 & 66.7 & $4+4$ & $\mathrm{~T} 2 \mathrm{c}$ & & 47.1 & $4+3$ & yes & yes \\
\hline 58 & 7.5 & 50.0 & $3+4$ & T1c & & 22.2 & $3+4$ & yes & yes \\
\hline
\end{tabular}

was conducted for stage pT3. We present data from the pre and postoperative phases pT2 (Table-1) and pT3 (Table-2).

\section{Preoperative Total PSA Serum Concentration between the Groups}

The first prognostic parameter assessed isolatedly or together with other factors was preoperative total PSA serum concentration. The PSA study showed that patients that had a prostateconfined disease (pT2) presented lower PSA rates $(7.5 \mathrm{ng} / \mathrm{mL})$ in relation to the group presenting extraprostatic disease $(\mathrm{pT} 3)(12.5 \mathrm{ng} / \mathrm{mL})(\mathrm{p}=0.002$; MannWhitney).

\section{Gleason Score}

For Gleason score of the biopsy, the results revealed that patients from group pT2 presented inferior mean values of Gleason when compared to patients in pT3 group ( $\mathrm{p}=0.006$; Mann-Whitney).

The comparison between the Gleason score of the biopsy and the surgical specimen, within the same group pT 2 or $\mathrm{pT} 3$, showed a significant statistical difference only for $\mathrm{pT} 2(\mathrm{p}=0.008$; Mann-Whitney). In pT2 group, $60 \%$ of the patients were sub-graduated, i.e., the biopsy Gleason score was inferior to the one of the surgical specimen, while for the pT3 group this percentage was only $10 \%$.

Gleason scores of the surgical specimen between pT 2 and pT 3 groups were statistically similar 
$(p>0.05)$. It is worth to mention that in both the predominant Gleason score was $3+4=7$ or superior.

\section{Positive Fragments of the Biopsy and Positive Blocks of the Surgical Specimen}

The study of the quantitative values obtained for the percentage of positive fragments of the biopsy showed that $\mathrm{pT} 2$ group patients presented an inferior mean percentage $(35.1 \%)$, when compared to pT3 group $(49.3 \%)(\mathrm{p}=0.049$; Mann-Whitney). A similar result was obtained for the percentage of positive blocks, indicating that the patients from pT2 group presented an inferior tumor volume $(32.9 \%)$ when compared to pT3 $(48.4 \%)(\mathrm{p}=0.015$; Mann-Whitney).

Specific analysis for $\mathrm{pT} 2$ groups between the percentage of positive fragments of the biopsy and the percentage of positive blocks of the surgical specimen, $(r=0.465 ; p=0.0385$; Spearman) or $\mathrm{pT} 3$ $(\mathrm{r}=0.576 ; \mathrm{p}=0.007$; Spearman $)$, revealed a weak positive correlation between both, demonstrating that the two variables tend to increase jointly.

\section{Biochemical Recurrence Associated To Prostatic Parameters in Both Pre and Postoperative Phases}

Biochemical recurrence varied considerably between pT2 and pT3 stages, being $20 \%$ and $70 \%$, respectively. The mean follow-up was of 22.8 months for pT2 stage and 24.4 months for pT3 stage. Among the prognostic parameters assessed the Gleason score (superior to 7), positive surgical margins and tumor volume, were associated to recurrence (Table-3).

The analysis of positive margins and complementary treatment in pT2 or pT3 stages, showed that the total positive margins of the surgical specimen influenced the need for complementary treatment, due to biochemical recurrence. For pT2 stage we have observed that, from the 7 patients with positive margins, 4 of them presented biochemical recurrence $(\mathrm{p}=0.007$; Fischer), while for $\mathrm{pT} 3$ this relations was 13 positive margins with 12 recurrences $(p=0.007$; Fischer). Among the 14 recurrences, in pT3 stage, 12 patients presented positive margins.

For the Gleason score parameter the patients were grouped in two categories ( $7<$ Gleason $\geq 7$ ). Among patients with a Gleason score equal or superior to 7 , at pT3 stage, 13 presented biochemical recurrence.

In relation to tumor volume, the data show that the patients that presented recurrence presented also a higher tumoral volume (54.3\% at pT3 stage).

\section{P53 and Ki-67 Expression}

The results for $\mathrm{p} 53$ and $\mathrm{Ki}-67$ were expressed in the percentage of labeled cells using the semiquantitative score method, based on the sum of the immunopositive tumor cells proportion and the intensity of the immunolabelling expression. On Tables-4 and

Table 3 - Clinical and morphologic variables associated to postoperative recurrence.

\begin{tabular}{lcccc}
\hline & With Recurrence (number) & \multicolumn{2}{c}{ Without Recurrence (number) } \\
\hline Variables & $\mathrm{pT} 2$ & $\mathrm{pT}$ & $\mathrm{pT} 2$ & $\mathrm{pT} 3$ \\
Positive margin & 4 & 12 & 3 & 2 \\
Negative margin & 0 & 2 & 13 & 5 \\
PSA $<10 \mathrm{ng} / \mathrm{mL}$ & 3 & 8 & 15 & 5 \\
PSA $>10 \mathrm{ng} / \mathrm{mL}$ & 1 & 6 & 1 & 1 \\
Gleason $<7$ & 2 & 1 & 6 & 1 \\
Gleason $>7$ & 2 & 13 & 32.5 & 37.9 \\
Estimated tumor volume $(\%)$ & 34.5 & 54.3 & & \\
\hline
\end{tabular}


Table 4 - Number of patients that present p53 nuclear expression in the biopsy and in the surgical specimen, in stages (pT2 and pT3). The columns refer to the percentage of cells with expression.

\begin{tabular}{lcccc}
\hline Stage & $\mathbf{0}$ to $\mathbf{5}$ & $\mathbf{6}$ to $\mathbf{1 0}$ & $\mathbf{1 1}$ to 20 & $\mathbf{2 0}$ \\
\hline pT2 biopsy & 12 & 3 & 3 & 2 \\
pT2 specimen & 20 & 0 & 0 & 0 \\
pT3 biopsy & 18 & 1 & 0 & 1 \\
pT3 specimen & 18 & 2 & 0 & 0 \\
\hline
\end{tabular}

Table 5 - Number of patients that present Ki-67 nuclear expression in the biopsy and in the surgical specimen, in stages (pT2 and pT3). The columns refer to the percentage of cells with expression.

\begin{tabular}{lcccc}
\hline Stage & $\mathbf{0}$ to $\mathbf{5}$ & $\mathbf{6}$ to $\mathbf{1 0}$ & $\mathbf{1 1}$ to 20 & $\mathbf{2 0}$ \\
\hline pT2 biopsy & 18 & 2 & 0 & 0 \\
pT2 specimen & 20 & 0 & 0 & 0 \\
pT3 biopsy & 17 & 2 & 1 & 0 \\
pT3 specimen & 18 & 0 & 2 & 0 \\
\hline
\end{tabular}

5, the uniform expression patterns are presented, independently from the stage (pT2 and pT3), both in the biopsy and in the surgical specimen.

\section{Expression of Chromogranin-A and Synaptofisin}

The expression of the immunomarkers, chromogranin-A and synaptofisin utilized to differentiate neuroendocrine cells was assessed qualitatively and classified as absent, light, moderate, intense and very intense. The results are presented on Tables- 6 and 7, for the different categories. A significant expression of these markers was observed, except in patients with compromised seminal vesicles.

\section{E-caderin Expression}

E-caderin was assessed both qualitatively and quantitatively with the respective expression forms (Figure-1). The results obtained showed a variability of the immunomarker. In most of the tissues assessed, including biopsies and surgical specimens, independently from the stage, the e-caderin expression was absent or the cytoplasmic pattern was predominant (Table-8). The usual membrane labeling, identified in normal epithelium, was rarely observed.

\section{PSA Expression}

The PSA molecular labeling presented a very intense expression with cytoplasmic granular pattern in all tissues from biopsies and from surgical specimens in pT3 stage.

\section{Molecular Markers and Recurrence}

For a global analysis between the recurrence of the disease and the profile of various molecular markers used, it was not possible to establish a correlation between these parameters. The expression of the molecular markers was similar for patients with or without recurrence. 
Table 6-Number of patients grouped in the different categories, based on the chromogranin-A expression in both stages (pT2 and pT3).

\begin{tabular}{lccccc}
\hline Stage & Absent & Light & Moderate & Intense & Very Intense \\
\hline pT2 biopsy & 12 & 4 & 2 & 1 & 0 \\
pT2 specimen & 18 & 0 & 1 & 1 & 0 \\
pT3 biopsy & 11 & 5 & 4 & 0 & 0 \\
pT3 specimen & 14 & 4 & 2 & 0 & 0 \\
\hline
\end{tabular}

Table 7 - Number of patients grouped in the different categories, based on the synaptofisin expression in both stages (pT2 and pT3).

\begin{tabular}{lccccc}
\hline Stage & Absent & Light & Moderate & Intense & Very Intense \\
\hline pT2 biopsy & 3 & 15 & 1 & 1 & 0 \\
pT2 specimen & 18 & 0 & 2 & 0 & 0 \\
pT3 biopsy & 14 & 4 & 1 & 1 & 0 \\
pT3 specimen & 15 & 5 & 0 & 0 & 0 \\
\hline
\end{tabular}

\section{COMMENTS}

The present work reinforces the importance of the prognostic parameters already consolidated in nomograms and exhaustively studied in large populations (14). However, the present sample suggests a late diagnosis when we aim at the cure by means of only one form of treatment, confirmed by the high tumor recurrence rate or residual disease in pT3 group.

Mean PSA in pT2 group of $7.5 \mathrm{ng} / \mathrm{mL}$ was divergent from the $12.5 \mathrm{ng} / \mathrm{mL}$ found for $\mathrm{pT} 3$ group. We have observed in both groups a higher levels of PSA, when compared to the cuff of values considered nowadays $(16,17)$.

Total-PSA serum concentration can be altered due to many factors, among which the patient's age and the prostate volume and cannot be considered isolatedly for tumor diagnosis. However, there are evidences that in a population with normal digital rectal examination and PSA between 0 and 4 $\mathrm{ng} / \mathrm{mL}, 15.2 \%$ present prostate cancer detected in the biopsy (18).

Gleason score has consolidated its importance as one of the most important prognostic factors in both pre and postoperative phases. A fact that deserves attention in the present sample is the trend to undergraduate the Gleason score in prostatic biopsy material, when compared to the Gleason score of the surgical specimen. An explanation, among other

Table 8 - Number of patients grouped in the different categories, based on the E-caderin expression in both stages (pT2 and pT3).

\begin{tabular}{lccc}
\hline Stage & Absent & Cytoplasmic & Membrane \\
\hline pT2 biopsy & 9 & 7 & 4 \\
pT2 specimen & 10 & 7 & 3 \\
pT3 biopsy & 14 & 5 & 1 \\
pT3 specimen & 16 & 4 & 0 \\
\hline
\end{tabular}



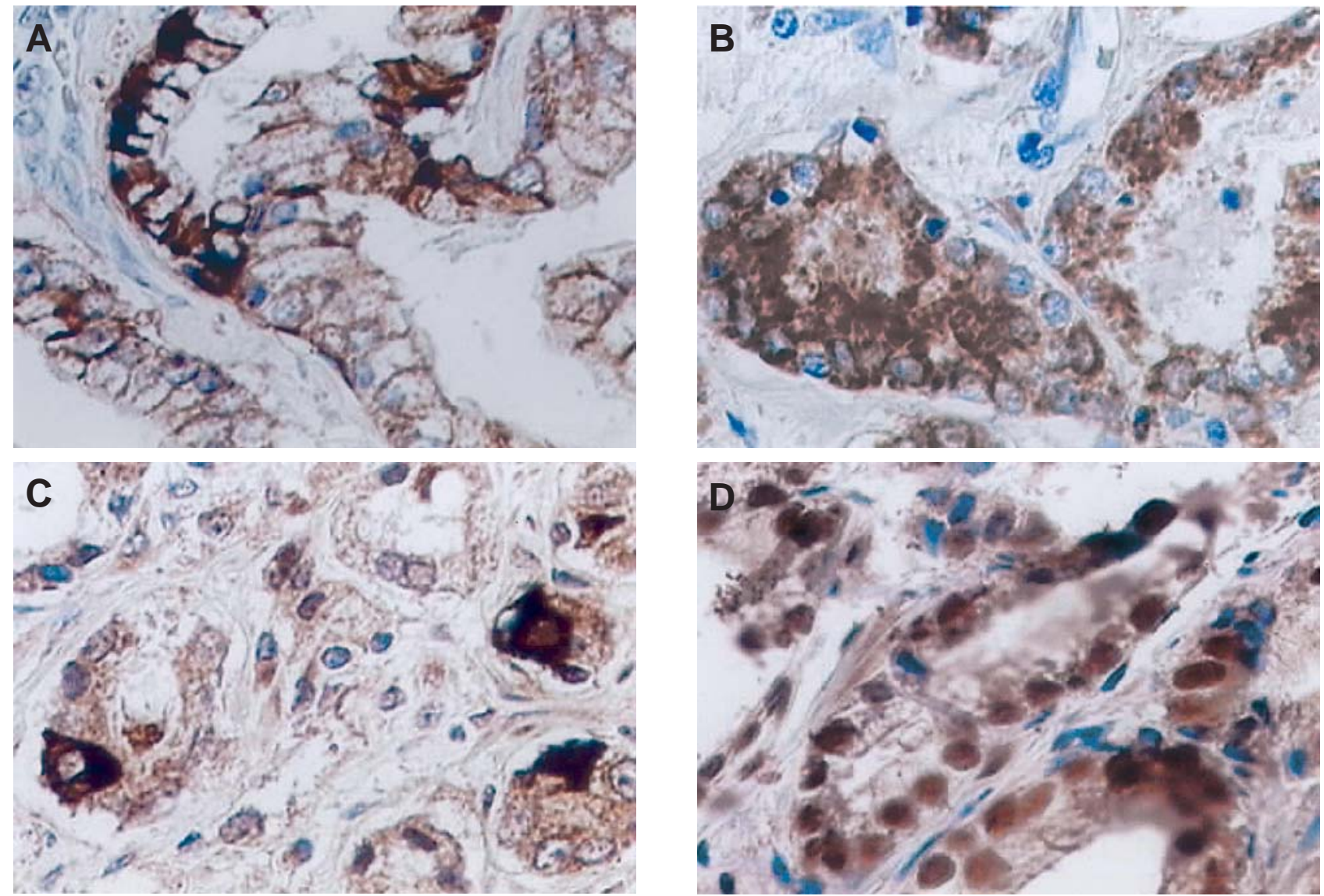

Figure 1 - Prostatic tumor with expression of different immunomarkers. A) Variation in the E-caderin expression, with focal membrane labeling and cytoplasmic pattern. B) Cytoplasmic expression of E-caderin with loss of membrane expression. C) Neuroendocrine differentiation with positivity for chromogranin-A. D) Strong nuclear expression for p-53.

variables, is that the limited sampling and the quality of the biopsy material, mainly when in phases where the disease is localized is represented by a small tumor volume. A growing tendency of the Gleason score was verified in pT3 group, confirming the correlation between the increases of the Gleason score with the worst prognostic (19).

Medial results obtained for the percentage of positive fragments reflected a difference in the extension of the tumor between the groups analyzed, being lower in pT2. Gancarczyk et al. showed this parameter to be of great relevance, mainly when associated to pre-treatment PSA and the higher Gleason score of the biopsy, suggesting to be a predictive factor of the pathological staging (20).
The results obtained for immunolabelling related to cellular proliferation, demonstrated a similar standard expression of p53 and Ki-67 in the biopsy and in the surgical specimen when both stages are compared.

The studies of Downing et al. (21) showed a significant association between the nuclear expression of mutant p53 and a higher risk of recurrence, or a lower disease-free survival. The p53 gene mutation blocks apoptosis induction (22). In this work, cellular proliferation markers, in prostatic biopsy, do not influence the prognostic factors related to the recurrence of the disease and compromised margins.

Neuroendocrine cells, usually positive for chromogranin-A are found sparsely in the prostatic 
tissue. This quantity can be increased or suffer changes, originating neuro-hormonal stimulations to the tumor microenvironment. Neuroendocrine differentiation in specimens from radical prostatectomies associated to the recurrence of the disease is still an open subject in literature. Some authors found a correlation (23), while others did not obtain the same results (24). Neuroendocrine cells are prominent in only 5 to $10 \%$ of the adenocarcinomas, having an important correlation with tumors presenting advanced stages. In gland-confined tumors, its expression does not correlate to the stage of the disease but with the Gleason score (25).

In the present study based on neuroendocrine cell immunomarkers chromogranin-A and synaptofisin, it was observed that in larger volume tumors with compromised seminal vesicle, there was a larger distinct expression or these markers, in two ways. It was observed a neuroendocrine differentiation of tumor cells and also a neuroendocrine cell hyperplasia in the normal tissue.

The PSA expression in pT3 stage was homogeneous and intense with cytoplasmic granular pattern in tissues from biopsies and surgical specimens. It was observed a lower coincident expression with tumors that presented a high Gleason score. Immunohistochemistry applied to PSA presents limitations, because the expression is observed in normal and neoplastic cells, showing that there is no correlation between serum concentration of this antigen and the intensity immunoreactivity of tissue. Immunohistochemistry for this marker can be useful as a method to assess its expression profile all through treatment (26).

The lack of E-caderin expression in the plasma membrane was observed in pT2 and pT3, with a percentage of 30 and $50 \%$ respectively. The lack of E-caderin expression relates to the advanced stage of the disease and metastasis. It is important to highlight that in certain metastatic tumors the E-caderin can return to its membrane expression. This finding remains without any clarification $(27,28)$. The lack of E-caderin expression is being related to a high Gleason score, according to the work of $\mathrm{Wu}$ et al. (29).

The immunolabelling profile in the present work cannot establish correlations of expressive differences for immunomarkers with neuroendocrine cell expressions and cell proliferation indicators. However, in relation to E-caderin, it was observed lack of expression related to the tumor tissue.

Positive margins with or without post radical prostatectomy extra-prostatic extension has been suffering a wide percentage variation as the medical literature registers (31). Basic influences that origin positive margins reside in the more or less rigorous criteria of selecting the surgical patient and in the surgical strategy utilized.

We have observed in our results a higher incidence of recurrence in the cases with positive surgical margins. All patients of pT2 group with recurrence of the disease presented positive peripheral surgical margins, demonstrating the importance of this parameter mainly in stages that characterize a localized disease. Positive margins in pT2 (35\%) and pT3 (65\%) groups should warn, based on the consolidated prognostic factors, changes in the surgical strategy (32). Positive surgical margin is represented by the tumor that reaches the previously stained surgical specimen surface, independently from having or not extra-prostatic extension.

When comparing the mean time of biochemical recurrence between both groups it is evident the negative impact originated by the presence of positive margins in pT3 group, predicting the need for complementary treatment in a disease with a worst prognostic. Also, in pT3 group, $20 \%$ of the patients presented positive seminal vesicle. Even though there has not been observed any preoperative risk factor suggesting this condition, prognostic factors such as PSA, histological grade and percentage of positive fragments in the biopsy, have been correlated with seminal vesicles involvement (33).

In our sample, among the 20 patients with pT2 disease, none was identified with $\mathrm{pT} 2 \mathrm{~b}$, reinforcing the difficulty of classifying such stage based on the surgical specimen (34).

It is worth to highlight that the 7 patients with positive margins and in the $\mathrm{pT} 2$ group did not present safe tissue parameters to evaluate the possibility of extra-prostatic extension. Thus, it remains the possibility that these patients were under staged and are in truth pT3. 
It is evident the need to improve new methods, predominantly morphologic and molecular, that are able to further exploit the study of the material from the prostatic biopsy. As to the profile of the molecular markers used in both studied groups, there was no significant difference in the sense of outlining an additional prognostic factor in the clinical practice.

\section{CONFLICT OF INTEREST}

None declared.

\section{REFERENCES}

1. Jemal A, Thomas A, Murray T, Thun M: Cancer statistics, 2002. CA Cancer J Clin. 2002; 52: 23-47. Erratum in: CA Cancer J Clin 2002; 52: 119. CA Cancer J Clin 2002; 52:181-2.

2. Hsing AW, Tsao L, Devesa SS: International trends and patterns of prostate cancer incidence and mortality. Int J Cancer. 2000; 85: 60-7.

3. Chatelard PP; Groupe De Travail Du: Standards, options and recommendations for the management of prostate cancer: therapeutic decision criteria. Bull Cancer. 2002; 89: 619-34. Erratum in: Bull Cancer. 2002; 89: 875.

4. Hull GW, Rabbani F, Abbas F, Wheeler TM, Kattan MW, Scardino PT: Cancer control with radical prostatectomy alone in 1,000 consecutive patients. J Urol. 2002; 167: 528-34.

5. Thompson IM, Pauler DK, Goodman PJ, Tangen CM, Lucia MS, Parnes HL, et al.: Prevalence of prostate cancer among men with a prostate-specific antigen level < or $=4.0 \mathrm{ng}$ per milliliter. N Engl J Med. 2004; 350: 2239-46. Erratum in: N Engl J Med. 2004; 351: 1470.

6. Partin AW, Kattan MW, Subong EN, Walsh PC, Wojno $\mathrm{KJ}$, Oesterling JE, et al.: Combination of prostatespecific antigen, clinical stage, and Gleason score to predict pathological stage of localized prostate cancer. A multi-institutional update. JAMA. 1997; 277: 144551. Erratum in: JAMA 1997; 278: 118.

7. Hernandez J, Thompson IM: Prostate-specific antigen: a review of the validation of the most commonly used cancer biomarker. Cancer. 2004; 101: 894-904.

8. Presti JC Jr, Shinohara K, Bacchetti P, Tigrani V, Bhargava V: Positive fraction of systematic biopsies predicts risk of relapse after radical prostatectomy. Urology. 1998; 52: 1079-84.

9. Djavan B, Remzi M, ZlottaA, Seitz C, Snow P, Marberger M: Novel artificial neural network for early detection of prostate cancer. J Clin Oncol. 2002; 20: 921-9.

10. Rubin MA: Using molecular markers to predict outcome. J Urol. 2004; 172: S18-21; discussion S212.

11. International Union Against Cancer (UICC): TNM Classification of malignant tumours. In: Sobin LH, Wittekind Ch (Eds.), sixth edition, New York, WileyLiss. 2002; pp. 184-7.

12. Srigley JR, Amin MB, Epstein JI, Grignon DJ, Humphrey PA, Renshaw AA, et al.: Protocol applies to invasive carcinomas of the prostate gland. In: http:// www.cap.org/apps/cap.portal?_nfpb=true \&_pageLabel=home. 2005.

13. AJCC cancer staging manual. In: Greene FL, Page DL, Fleming ID (eds.), sixth edition, New York, Springer. 2002; pp.337-46.

14. Diblasio CJ, Kattan MW: Use of nomograms to predict the risk of disease recurrence after definitive local therapy for prostate cancer. Urology. 2003; 62 Suppl 1: 9-18.

15. Djavan B \& Lange P: Epidedmiology, screening and biomarkers for prostate cancer. Prostate Cancer annual updating. 2005. Vol. 3 - 41.

16. Bahnson RR, Hanks GE, Huben RP, Kantoff P, Kozlowski JM, Kuettel M, et al.: NCCN Practice Guidelines for Prostate Cancer. Oncology. 2000; 14: 1119.

17. Krumholtz JS, Carvalhal GF, Ramos CG, Smith DS, Thorson P, Yan Y, et al.: Prostate-specific antigen cutoff of $2.6 \mathrm{ng} / \mathrm{mL}$ for prostate cancer screening is associated with favorable pathologic tumor features. Urology. 2002; 60: 469-73.

18. Chan TY, Chan DY, Stutzman KL, Epstein JI: Does increased needle biopsy sampling of the prostate detect a higher number of potentially insignificant tumors? J Urol. 2001; 166: 2181-4.

19. Gleason DF, Mellinger GT: Prediction of prognosis for prostatic adenocarcinoma by combined histological grading and clinical staging. J Urol. 1974; 111:58-64.

20. Gancarczyk KJ, Wu H, McLeod DG, Kane C, Kusuda L, Lance R, et al.: Using the percentage of biopsy cores positive for cancer, pretreatment PSA, and highest biopsy Gleason sum to predict pathologic stage after radical prostatectomy: the Center for Prostate Disease Research nomograms. Urology. 2003; 61: 589-95. 
21. Downing SR, Russell PJ, Jackson P: Alterations of p53 are common in early stage prostate cancer. Can J Urol. 2003; 10: 1924-33.

22. Borre M, Stausbol-Gron B, Overgaard J: p53 accumulation associated with bcl-2, the proliferation marker MIB-1 and survival in patients with prostate cancer subjected to watchful waiting. J Urol. 2000; 164: 716-21.

23. Theodorescu D, Broder SR, Boyd JC, Mills SE, Frierson HF Jr: p53, bcl-2 and retinoblastoma proteins as longterm prognostic markers in localized carcinoma of the prostate. J Urol. 1997; 158: 131-7.

24. Ahlegren G, Pedersen K, Lundberg S, Aus G, Hugosson $\mathrm{J}$, Abrahamsson P: Neuroendocrine differentiation is not prognostic of failure after radical prostatectomy but correlates with tumor volume. Urology. 2000; 56: 1011-5.

25. Cerovic SJ, Brajuskovic GR, Vukotic Maletic VD, Micic SR: Neuroendocrine differentiation in prostate cancer. Vojnosanit Pregl. 2004; 61: 513-8.

26. Karseladze AI, Rytin IIe, Budunova IV: Immunohistochemical study of the prostate-specific antigen in prostatic cancer. Arkh Patol. 2004; 66: 3-7.

27. De Marzo AM, Knudsen B, Chan-Tack K, Epstein JI: E-cadherin expression as a marker of tumor aggressiveness in routinely processed radical prostatectomy specimens. Urology. 1999; 53: 707-13.

28. Isaacs JT, Isaacs WB: Androgen receptor outwits prostate cancer drugs. Nat Med. 2004; 10: 26-7.

29. Wu HC, Lai MT, Wu CI, Chen HY, Wan L, Tsai FJ, et al.: E-cadherin gene 3'-UTR C/T polymorphism is associated with prostate cancer. Urol Int. 2005; 75: 350-3.

30. Wieder JA, Soloway MS: Incidence, etiology, location, prevention and treatment of positive surgical margins after radical prostatectomy for prostate cancer. J Urol. 1998; 160: 299-315.

31. Swindle P, Eastham JA, Ohori M, Kattan MW, Wheeler T, Maru N, et al.: Do margins matter? The prognostic significance of positive surgical margins in radical prostatectomy specimens. J Urol. 2005; 174: 903-7.

32. Koh H, Kattan MW, Scardino PT, Suyama K, Maru N, Slawin K, et al.: A nomogram to predict seminal vesicle invasion by the extent and location of cancer in systematic biopsy results. J Urol. 2003; 170: 1203-8.

33. Quintal MM, Magna LA, Guimaraes MS, Ruano T, Ferreira U, Billis A: Prostate cancer pathologic stage pT2b (2002 TNM staging system): does it exist? Int Braz J Urol. 2006; 32: 43-7.

\section{Correspondence address:}

Dr. José Carlos de Almeida

SQS 313 Bloco J Ap. 404

Brasília, DF, 70382-100, Brazil

Fax: + 55 613346-1592

E-mail: jcalmeidadf@terra.com.br 